堆 積 学 研 究, 42号, 29-32, 1995

J. Sed. Soc. Japan, No. 42，29-32，1995

\title{
Remarks on the present state of sedimentary geology in Japan from a Scandinavian perspective
}

\author{
W. Nemec * \\ (Geological Institute, University of Bergen, N-5007 Bergen, Norway)
}

I have had the pleasure of spending recently 5 weeks in Japan (November-December 1994) as a sedimentologist and a research fellow of the Japan Society for the Promotion of Science. I have visited several universities in Honshu and Kyushu, attended the Annual Meeting of the Sedimentological Society of Japan in Mito and met with sedimentologists from some 15 geological departments and related earth-science institutions. After having submitted duly my report to the J. S. P. S., I have been invited to publish my remarks in an open form to share them with the Japanese colleagues. I have willingly accepted this invitation, although I am well aware that my observations are very incomplete and my personal thoughts and impressions from the visit are necessarily subjective.

In my opinion, the present-day state of sedimentary geology in Japan is remarkably good and fully comparable with the state of this discipline in Europe and the U.S. A. My specific comments and minor critical remarks are as follows.

$\square$ There is a plenty of very interesting and original research being done by Japanese sedimentologists, and I have benefited enormously by meeting many of them personally in their own research "kitchens". I dare to say that the Japanese sedimentary geology, much like the Japanese cuisine, has its own special flavour - in both intellectual and thematic sense - and it is simply impossible not to enjoy and admire it. I have met great many accomplished sedimentologists and learnt a great deal of new things during the visit, also in the field.

$\square$ The Japanese sedimentology seems to have developed a good balance between the rock-oriented field studies and experimental research, with the latter including both laboratory work and the research on modern sedimentary environments. Japanese sedimentologists have traditionally played a prominent role in pioneering the application of mathematical methods and in contributing to the deep-sea research, including the ODP programmes. However, the active interest of Japanese researchers in modern sedimentary processes is clearly much broader today and includes both marine and terrestrial environments. This puts the Japanese sedimentologists in a quite favourable position relative to their European colleagues, whose activities are still lagging far behind the various needs dictated by the recent awareness of world-wide environmental problems. In my opinion, this "environmental" trend in Japanese sedimentology should further be encouraged and strengthened, also by the development of a closer collaboration with geomorphologists and the promotion of more comprehensive, "integrated" environmental research programmes. The younger Japanese researchers should then try to win this card by applying for scholarships and research fellowships abroad, particularly in Europe, where environmental studies are presently given priority.

My observations leave little doubt that the Japanese sedimentologists are highly devoted to their research, working very intensively and spending much more time in their offices than their European colleagues would normally do. (According to my estimate, a Japanese researcher on the average spends daily ca. $20-30 \%$ more time in the office. ) Also, the working space, office conditions and available technical service at the geological departments in Japan are often poorer than in the similar university departments in the Western European countries, especially Scandinavian, whose general economic status is comparable to or lower than that of Japan. For 
comparison: In my geological department in Bergen, there are 25 academics with permanent positions and some 30 doctoral students and research fellows. Our service staff includes 15 technicians and 7 persons of secretarial personnel. Each of the 47 employees has a well-furnished, air-conditioned, thermostaticallyheated room of ca. $12 \mathrm{~m}^{2}$, and the doctoral students and postdoctoral fellows share such rooms in two. Few of the geological departments of the Japanese state universities come even close to such working conditions (which, still, none of us in Bergen would consider to be particularly comfortable or "luxurious"). In short, the Japanese academic researchers are far from being spoiled by any office comforts and a considerable portion of their working time appears to be consumed by various kinds of technical and administrational work. The latter is minimized in our Scandinavian university departments by the employment of adequate service personnel. For comparison, no more than $10-15 \%$ of my annual working time goes to administration matters, whereas my Japanese colleague in a similar position may reportedly use up to $50-60 \%$ of his time for activities that are neither research nor education. From a European perspective, it would thus appear, without much exaggeration, that a Japanese professor is forced by his system to do two jobs for the salary of one.

Japan is one of the countries where the sedimentologists can still enjoy a kind of "absolute freedom" of research, even if some may not even fully realize or appreciate it. My Japanese colleagues can still afford to do exclusively the "pure" basic research and follow quite freely their personal scientific interests. In contrast to many European countries as well as the U.S. A. and Canada, the sedimentological research in Japan is not bounded by any industrial or oil-company funding and the researchers are thus totally free in choosing their research topics. In short, they are the sole chefs in their semi-private research "kitchens", and they cook whatever comes to their minds; their kitchens are far from being restaurants. This rather unique situation has many important advantages, as it gives ground for original research and allows the testing of new concepts, even if time-consuming, uncertain or controversial; the researchers don't have to undertake "routine" studies or projects that are not in the mainstream of their personal interests. However, this situation necessarily bears also some disadvantages. For example, there is little personal co-operation and the Japanese sedimentologists cannot also easily compete for foreign research grants and fellowships, simply because the financial priority abroad is commonly given to "applied" research, oriented towards petroleum or other industry. Likewise, the geological education programmes of Japanese universities lack the "applied" aspects and industry-oriented courses. For example, the Japanese petroleum industry appears to be running their own post-graduate education programmes in petroleum geology, like it was in the Western European countries some 15 or 20 years ago. There is little doubt that the Japanese sedimentary geologists, with their high skills in numerical methods, could make a considerable international contribution in areas like petroleum reservoir modelling. It is, therefore, a pity that this great "latent" potential of Japanese researchers has never been activated by either the local petroleum industry or the researchers' personal interest in collaboration with foreign oil companies. Likewise, it is a pity that the university education programmes in sedimentary geology are not designed to render the graduates more competitive on the international job market or give them some good basis for possible work as international industry consultants.

Japanese sedimentological research is well-recognized internationally, and is visible on the international scientific scene much more than that of, say, Australia, New Zealand, Russia, China and many European countries. There has also been a notable increase in the number of Japanese sedimentological contributions in the international journals and non-periodic publications in the last few years. However, the actual "export potential" of the Japanese sedimentological research is still much higher. During my visit, I have come across very many exciting studies that have only been published in the local journals, mainly in Japanese, and are virtually unknown abroad. Of course, it is both natural and easier for a researcher to write in the native language 
and publish in the national journals; but it is also a great waste of the national scientific potential and research funds. Our research tends to be increasingly more specialized today, and the pertinent question then is as to how many readers can a specialized paper, even if brilliant, find in a given country in a short term ? In a country like Japan, probably less than 10 and possibly up to 20 at the best. Yet, how many of those readers will actually refer to a particular paper or follow it up with their own research ? In short, the global impact of the Japanese sedimentological research could, and should, be much greater than it is today. One could think of many practical remedies that would encourage Japanese researchers to publish more papers internationally (for example, a rule might be set that each research grant must result in at least one paper in an international journal before a new grant could be received; the travel grants to main conferences and congresses abroad might bear the same requirement; the publications in international journals might be ranked higher in the employment and personal promotion system; etc. ). In my opinion, the administrators of Japanese science should probably give more thought to this serious problem.

A similar critical remark pertains to the Japanese science publishers concerned with geology. On the office shelves of my Japanese colleagues, I have seen many locally-published books in English, which would almost certainly sell well abroad, but are quite unknown there. I have seen also several books in Japanese, but with a scope sufficiently broad to attract international readership. This kind of publishing and marketing policy, if such exists, is rather regretable. The main Japanese science publishers, such as the University of Tokyo Press, the Tokai University Press and the Japanese Geological Survey Publications, should make more effort to publish in English and to advertise and sell their products abroad. For example, I have never come across any single leaflet advertising Japanese English-language publications in Europe, and I doubt whether such leaflets or catalogues are being distributed in other parts of the world either.

$\square$ The geological setting of Japan, as a young island arc, is fascinating and rather unique, and many Japanese sedimentary geologists are using this natural attribute quite well in their research - as an added value to their studies and publications.

The Japanese Islands are an important modern analogue for many ancient plate-tectonic settings and regional cases world-wide, which renders Japanese geological research particularly attractive abroad. It is a pity, therefore, that the interest of so many Japanese sedimentologists, instead of focusing on the geological uniqueness of Japan, appears to be drifting passively towards some global "fashions" and non-specific foreign research trends. I was rather surprised to see how little "Japanese", in fact, the Japanese sedimentary geology appears to be today. For example, Japan can well be regared to be a kind of melange paradise, where the rest of us concerned with orogenic belts should come to learn from, yet the Japanese contribution to the topic of melanges and olistostromes has been surprisingly meagre. The last two international volumes on this topic came out without a single Japanse contribution, and I have seen no more than 3 (three) papers by Japanese authors, none of them a sedimentologist, in the international journals in the last 5 years or so. In my opinion, it might be beneficial to define a number of national research programmes devoted to particular regional topics and then give some financial priority to projects that subscribe directly to these regional programmes.

$\square$ Perhaps, the greatest surprise to me was to see the apparent lack of co-operation between sedimentologists from different Japanese universities or other research institutions. It was rather unexpected for me to see how highly "individualistic" the Japanese researchers are, although they are quite "lonely", if not isolated, in their departments, their research funds are limited and generally difficult to obtain, and yet their research interests are often similar or even coalescing. This situation would seem to be begging for joint, collaborative research projects (vide the British universities, whose sedimentologists have found themselves "home alone", too, after the far-going recent reform). Unfortunately, such joint ventures in Japan are apparently quite rare. As a result of their isolation, personal specialization and heavy 
work-load, the Japanese researchers seem also to have a relatively narrow interest when it comes to the scientific literature and other people's research work, even within Japan. In short, the Japanese science system fails to stimulate co-operation and the development of what we call in Europe a "Renaissance-type" scientist (even if such is no longer achieveable at the present stage of science development). Likewise, there seems to be surprisingly little interdisciplinary co-operation, even in cases clearly begging for such contacts. For example, I was surprised to see so little co-operation between fluvial sedimentologists and geomorphologists; between the sedimentologists concerned with mass-flow deposits and the geomorphologists of the Disaster Prevention Research Institute, Kyoto University; or between the sedimentologists and the fluid-flow researchers of the Tokyo Institute of Technology. Paradoxically, the work of that "other side" often seems to be better known and more appreciated abroad than by the sedimentologists at home. Again, some practical remedies should probably be found to stimulate more co-operation on the national level, for example - by giving financial priority to projects involving researchers from two or more universities. This tactics of "research economization" is used in many European countries and has recently been adopted also by the European Union's science foundations to stimulated international collaboration within Europe.

Despite these few misgivings, which are by no means uniquely related to Japan, I have to conclude that the Japanese sedimentary geology is in quite good health and its future is in the hands of some very talented and energetic young researchers. There are great many brilliant and highly enthusiastic young sedimentologists, thanks to the inspiration and educational work of the great "old" masters, and it is not an exaggeration to say that the Japanese sedimentology has a very high international standing and currently ranks at the same level as the European, Canadian or Australian. The impressive laboratory work that I have seen, if further developed and co-ordinated, gives a clear prospect for a new "powerhouse" of experimental sedimentology, which many of us, foreign researchers, will be looking up to in the years to come.

In summary, the J. S. P. S. Fellowship programme is an important and absolutely splendid way to promote the Japanese science (and culture!) abroad and to stimulate contacts between the Japanese and foreign scientists. My visit's programme was extremely rich and very meticulously prepared by my principal host, Prof. Hakuyu Okada. I have been greatly impressed by Japan, her extremely rich and admirable culture, and the remarkable hospitality of my Japanese colleagues. I must say that - despite my prior knowledge of Japanese research from the literature - I have truly "discovered" Japanese sedimentology for myself and my European colleagues. I have benefited enormously from the visit, in both scientific and cultural sense, and I have many new friends with whom I will certainly stay in contact and probably collaborate in the near future. I am very grateful to the J. S. P. S. and my hosts for giving me this opportunity, and I will do my best to "advertise" Japanese sedimentology in Europe. 